\title{
Antibiotic drug resistance pattern of uropathogens seen in the first episode of community-acquired pediatric urinary tract infections at a tertiary care hospital
}

\section{Eyup Sari}

Doktor Sami Ulus Cocuk Hastanesi: SBU Ankara Dr Sami Ulus Kadin Dogum Cocuk Sagligi ve Hastaliklari Egitim ve Arastirma Hastanesi

\section{Fatma Yazilitas}

Doktor Sami Ulus Cocuk Hastanesi: SBU Ankara Dr Sami Ulus Kadin Dogum Cocuk Sagligi ve Hastaliklari Egitim ve Arastirma Hastanesi

\section{Fatma Zehra Oztek Celebi ( $\sim$ z_oztek@yahoo.com)}

Dr Sami Ulus Kadın Doğum Çocuk Sağlığı ve Hastalıkları Eğitim ve Araştırma Hastanesi: SBU Ankara Dr Sami Ulus Kadin Dogum Cocuk Sagligi ve Hastaliklari Egitim ve Arastirma Hastanesi https://orcid.org/0000-0002-2203-5904

\section{Meltem Akcaboy}

Doktor Sami Ulus Cocuk Hastanesi: SBU Ankara Dr Sami Ulus Kadin Dogum Cocuk Sagligi ve Hastaliklari Egitim ve Arastirma Hastanesi

\section{Ozlem Akisoglu}

Doktor Sami Ulus Cocuk Hastanesi: SBU Ankara Dr Sami Ulus Kadin Dogum Cocuk Sagligi ve Hastaliklari Egitim ve Arastirma Hastanesi

\section{Saliha Senel}

Doktor Sami Ulus Cocuk Hastanesi: SBU Ankara Dr Sami Ulus Kadin Dogum Cocuk Sagligi ve Hastaliklari Egitim ve Arastirma Hastanesi

\section{Research}

Keywords: urinary tract infection, uropathogen, antimicrobial resistance, antimicrobial susceptibility

Posted Date: March 10th, 2021

DOI: https://doi.org/10.21203/rs.3.rs-269767/v1

License: (a) (1) This work is licensed under a Creative Commons Attribution 4.0 International License. Read Full License 
Version of Record: A version of this preprint was published at Turkish Journal of Pediatric Disease on March 9th, 2022. See the published version at https://doi.org/10.12956/tchd.1071855. 


\section{Abstract}

\section{Background}

Increased antibiotic resistance is a significant problem associated with higher morbidity, mortality, and costs in managing urinary tract infections (UTI). This study aims to analyze the antimicrobial resistance profile of uropathogens isolated from children with the first attack of community-acquired UTI.

\section{Materials and Methods}

This retrospective cohort study was conducted between January 2010-December 2016, with the patients aged one month to 18 years diagnosed with the first attack of community-acquired UTI at the pediatric outpatient clinic of a tertiary care hospital. Patients' age, sex, UTI history, clinical findings at admission, urine analysis, urine culture, and antibiogram results were recorded.

\section{Results}

A total of 1086 patients and 1086 cultures were included in the study. The male/female ratio was 1/5.3. The mean age of the children was $73.7 \pm 47.1(0.4-215.9)$ months. $16.0 \%$ were aged $1-24$ months. $E$. coli was the most common causative agent found to be $85.1 \%$ in frequency. The overall antimicrobial resistance was found to be highest for ampicillin, followed by piperacillin and trimethoprimsulfamethoxazole $(63.5,41.6$ and $38.1 \%$, respectively). Imipenem, amikacin, and tobramycin had the least resistance $(0.5,0.5$, and $7.6 \%$, respectively). The overall antimicrobial resistance against amoxicillinclavulanate, ampicillin-sulbactam, cefuroxime, ceftriaxone was 19.4, 24, 25.9 and $21.1 \%$; respectively.

Extended-spectrum beta-lactamase positivity was detected in $5.6 \%(n=61)$ of samples.

\section{Conclusion}

Our study showed significant increase in antimicrobial resistance to the most common antibiotics which are prescribed before urine culture results and antibiotic sensitivities are available. The resistance rates for amoxicillin-clavulanate, ampicillin-sulbactam, cefuroxime, ceftriaxone were almost $20 \%$ or above in children with the first UTI attack in an outpatient setting.

\section{Introduction}

Urinary tract infections (UTI) are among the most common bacterial infections in children. ${ }^{1}$ Escherichia coli is the most common bacterial pathogen responsible for UTI. ${ }^{1,2}$ One lingering effect of childhood UTI is that it can damage the growing kidney by forming kidney scarring associated with long-term complications, hypertension, and renal failure. ${ }^{1-4}$ Clinical guidelines about UTI in children encourage rapid diagnosis and early treatment with an appropriate agent to prevent kidney scarring and long-term complications. ${ }^{4-7}$ Antibiotic resistance is strikingly increasing among the uropathogens, and bacterial resistance causes problems for clinicians due to limited treatment options. ${ }^{1,2,6,7}$ Data are available on the 
antimicrobial susceptibility patterns of endemic uropathogens in different countries of the world, but it is necessary to update the changing patterns of resistance to determine the appropriate treatment plans. ${ }^{1,2,6-9}$ Since treatment to reduce UTI-related morbidity is usually started early before the results of urinary microbiology are obtained, current data on the most common uropathogens and local antibiotic resistance patterns will help to choose accurate empirical therapy.

This study was conducted to determine the antimicrobial resistance patterns of uropathogens isolated from patients with the first episode of community-acquired urinary tract infections to choose appropriate empirical UTI treatment in children. To our knowledge, this is the only study examining antimicrobial resistance patterns in the first UTI episode in children.

\section{Materials And Methods}

This observational study was conducted between January 2010-December 2016, with children aged one month to 18 years diagnosed with their first episode of UTI at pediatric outpatient polyclinics at Dr. Sami Ulus Children's Health and Diseases Training and Research Hospital. Ankara Hematology-Oncology Hospital Ethics Committee approved the study.

Urine samples for microbial examination were collected by midstream clean-catch method in the toilettrained and urethral catheterization method in non-toilet-trained children. No samples in the study were collected by the bag or suprapubic aspiration. A positive urine culture was defined as the growth of a single pathogen of at least $10^{5}$ colony forming units (CFU)/ml for midstream sampling, and $10^{4}$ colonies/ml for catheter specimens. ${ }^{10}$

Only a single positive culture per patient was included in the analysis. The diagnosis of UTI was then based on clinical findings and positive urine culture.

Children with urinary tract abnormalities, recurrent UTIs, vesicoureteral reflux (VUR), urolithiasis, complicated urinary tract infections, known chronic or other medical disorders, polymicrobial culture results, culture results defined as contamination by medical microbiology expert and using antibiotics before admission or already on antibiotic treatment and hospitalized children were excluded from the study.

All urine samples were tested using standard procedures and were cultivated into MacConkey agar and incubated at $37^{\circ} \mathrm{C}$ for $48 \mathrm{~h}$. The VITEK 2 automated microbial identification system was used to identify uropathogens and antimicrobial "susceptible" or "resistant" status.

Bacterial identification and the determination of sensitivity and resistance patterns of these microorganisms were assessed by the criteria established by the Clinical Laboratory Standards Institute (formerly National Committee for Clinical Laboratory Standards) guidelines. ${ }^{11}$ Patients' sex, age, clinical findings, urine analysis (UA), urine culture and susceptibility rates of etiologic agents to different antimicrobials were recorded retrospectively. The patients' previous UTI history was asked to parents and 
checked by hospital records if they had applied to our hospital before. Patients were classified as E. Coli and non-E. Coli UTI, according to urine culture results. Statistical analysis was performed in SPSS for Windows 15.0 (SPSS Inc., Chicago, IL, USA). Descriptive statistics are given as mean, the standard deviation for continuous variables, and frequency, the percentage for categorical variables. Comparisons were performed using the t-test, Mann-Whitney u test, and chi-squares test, where $p<0.05$ was considered as statistically significant.

\section{Results}

\section{Clinical and demographic characteristics}

The 1086 cultures of 1086 patients with first UTI episodes were enrolled in the study. Of these patients; $15.8 \%(n=172)$ were male, $84.2 \%(n=914)$ were female. The male/female ratio was $1 / 5.3$. The number of girls was significantly higher than boys $(P<0.001)$. The mean age was $73.7 \pm 47.1(0.4-215.9)$ months. Of the 1086 positive UCs, $16.0 \%$ ( $n=174)$ were from children aged $1-24$ months. $82.4 \%$ of UCs were obtained by midstream clean catch. $17.6 \%$ were obtained by catheterization. Demographical and clinical characteristics were shown in Table 1. UTI with non- $E$. Coli isolates were younger than patients with UTI with E. coli isolates, more seen in males, and had more normal urinalysis (Table 2). 
Table 1

Demographic characteristics of the patients

\begin{tabular}{|ll|}
\hline The mean age & $73.7 \pm 47.1(\mathbf{0 . 4 - 2 1 5 . 9 )}$ months \\
\hline Age groups & $\%(\mathrm{n})$ \\
$<2$ years & $16.0(174)$ \\
$2-5$ years & $27.3(296)$ \\
$6-10 y e a r s$ & $43.0(467)$ \\
$11-18$ years & $13.7(149)$ \\
\hline Sex & $\%(\mathrm{n})$ \\
Male & $15.8(172)$ \\
Female & $84.2(914)$ \\
\hline Symptoms & $\%(\mathrm{n})$ \\
Fever & $72.7(789)$ \\
Urinary complaints & $27.0(293)$ \\
Abdomen/flunk pain & $6.1(67)$ \\
Vomiting & $3.4(38)$ \\
Irritability & $4.4(48)$ \\
Other (malnutrition, prolonged jaundice) & $3.2(35)$ \\
Urine analysis & $\%(\mathrm{n})$ \\
Positive nitrite & $52.0(557)$ \\
Positive leukocyte esterase (LE) & $77.6(846)$ \\
Nitrite and LE positivity & $42.2(452)$ \\
Normal urine microscopy & $12.5(134)$ \\
Normal results in urinalysis and microscopy & $7.8(84)$ \\
\hline
\end{tabular}


Table 2

Demographic and clinical characteristics of E. Coli and nonE. Coli groups

\begin{tabular}{|llll|}
\hline Characteristics & E. Coli & Non-E. Coli & P-value \\
\hline Mean age (years) & $6.3 \pm 3.7$ & $4.7 \pm 4.4$ & $<0.01$ \\
\hline$<2$ years of age (\%) & 13.1 & 32.3 & $<0.01$ \\
\hline Male sex (\%) & 9.8 & 49.3 & $<0.01$ \\
\hline Fever positive (\%) & 21.4 & 14.8 & 0.056 \\
\hline Normal urinanalysis & 5.8 & 19.3 & $<0.01$ \\
\hline
\end{tabular}

\section{Isolated uropathogens}

E. coli $(85.1 \%, \mathrm{n}=924)$ was the most common causative agent in all age groups followed by Proteus species $(7.6 \%, n=82)$, and Klebsiella species $(6.5 \%, n=71)$. Other isolates (M. morgagni, Enterobacter, Streptecocspp, S. aureus) were $0.9 \%(n=9)$ in frequency ( Table 3$)$. 
Table 3

Antibiotic resistance frequencies according to isolated uropathogens

\begin{tabular}{|lllll|}
\hline Antibiotics & $\begin{array}{l}\text { E. Coli } \\
\text { ( }(\mathbf{n})\end{array}$ & $\begin{array}{l}\text { Proteus } \\
\%(\mathbf{n})\end{array}$ & $\begin{array}{l}\text { Klebsiella } \\
\%(\mathbf{n})\end{array}$ & $\begin{array}{l}\text { Total UCs } \\
\%(\mathbf{n})\end{array}$ \\
\hline Ampicillin & $62.7 \%(561)$ & $41.8 \%(33)$ & $95.8(68)$ & $63.5 \%(668)$ \\
\hline Piperacillin & $44.5 \%(182)$ & $9.1 \%(3)$ & $39.4(13)$ & $41.6 \%(198)$ \\
\hline Amoxicillin-clavulanate & $19.4(173)$ & $7.5(6)$ & $33.3(23)$ & $19.8 \%(208)$ \\
\hline Ampicillin-sulbactam & $24.6(216)$ & $5.2(4)$ & $36.2(25)$ & $24 \%(248)$ \\
\hline Piperacillin-tazobactam & $11.1(67)$ & $1.7(1)$ & $17.3(9)$ & $10.9 \%(78)$ \\
\hline Aztreonam & $19.3(107)$ & $0(0 / 37)$ & $35.4(17)$ & $19.4 \%(124)$ \\
\hline Cephazolin & $16.5(94)$ & $9.3(5)$ & $27.7(13)$ & $16.9 \%(114)$ \\
\hline Cephalotin & $29.2(142)$ & $11.9(5)$ & $30(12)$ & $28.2 \%(161)$ \\
\hline Cefepime & $12.3(64)$ & $0(0 / 40)$ & $13.5(5)$ & $11.4 \%(69)$ \\
\hline Cefuroxime & $25.4(156)$ & $11.4(5)$ & $38.3(18)$ & $25.9 \%(184)$ \\
\hline Cefixime & $18.9(10)$ & $0(0 / 20)$ & - & $17.5 \%(10)$ \\
\hline Ceftriaxone & $21.5(37)$ & $0(0 / 46)$ & $35.2(19)$ & $21.1 \%(157)$ \\
\hline Cefotaxime & $10.7(55)$ & $0(0 / 40)$ & $30.8(12)$ & $11.3 \%(67)$ \\
\hline Ceftazidime & $21.1(128)$ & $0(0 / 46)$ & $36.7(18)$ & $20.7 \%(146)$ \\
\hline Nitrofurantoin & $5.5(22)$ & $94.3(33)$ & $33.3(10)$ & $14.4 \%(68)$ \\
\hline Trimethoprim-sulfamethoxazole & $37.5(336)$ & $52.6(41)$ & $32.9(23)$ & $38.1 \%(400)$ \\
\hline Gentamicin & $9.5(86)$ & $5.1(4)$ & $14.1(10)$ & $9.5 \%(100)$ \\
\hline Amikacin & $0.5(4)$ & $2.4(2)$ & $1.4(1)$ & $0.5 \%(5)$ \\
\hline Tobramycin & $7.7(33)$ & $2.6(1)$ & $11.4(4)$ & $7.6 \%(38)$ \\
\hline Imipenem & $0.4(2)$ & $0(0 / 39)$ & $2.6(1)$ & $0.5 \%(3)$ \\
\hline Ciprofloxacin & $9.1(68)$ & $1.5(1)$ & $8.1(5)$ & $8.4 \%(74)$ \\
\hline
\end{tabular}

\section{Antibacterial susceptibility}

Among all isolates, the overall antimicrobial resistance was found to be highest for ampicillin, followed by piperacillin and TMP-SMX $(63.5,41.6$, and $38.1 \%$, respectively). The overall antimicrobial resistance 
against amoxicillin-clavulanate, ampicillin-sulbactam, cefuroxime, ceftriaxone was 19.4, 24, 25.9, and $21.1 \%$; respectively. Imipenem, amikacin, and tobramycin had the least resistance $(0.5,0.5$, and $7.6 \%$, respectively). The antimicrobial resistance patterns of the uropathogens were shown in Table 3.

E. coli demonstrated high resistance to ampicillin, piperacillin, and TMP/SMX $(62.7,44.5$, and $37.5 \%$, respectively). The least resistance was for imipenem and amikacin and nitrofurantoin $(0.4,0.5,5.5 \%$, respectively) (Table 3 ).

Proteus spp represented high resistance to nitrofurantoin, TMP-SMX, and ampicillin (94.3, 52.6, and $41.8 \%$, respectively). Proteus spp had no resistance against third-generation cephalosporins and imipenem (Table 3).

Klebsiella spp had the highest resistance to ampicillin (95.8\%). Cephalosporins other than cefepime and cephazolin had a resistance frequency of $\geq 30 \%$. The least resistance was for amikacin, imipenem, and ciprofloxacin. $(1.4,2.6,8.1 \%$, respectively) (Table 3). The extended-spectrum beta-lactamase (ESBL) producer isolates were detected in 61 samples $(5.6 \%, n=61 / 1086)$. Of these, $n=55$ were among E. coli isolates, $n=6$ were among Klebsiella species. Extended-spectrum beta-lactamase positive strains showed high resistance to ampicillin (100\%), ceftriaxone (96.5\%), and nitrofurantoin (33.3\%). They revealed the least resistance for amikacin (8.5\%) and imipenem (7.1\%).

\section{Discussion}

Uropathogens are showing a rising trend in the antimicrobial resistance throughout the world. ${ }^{2,7,8,12-20}$ The most common oral antibiotics prescribed for UTI as empirical antimicrobial agents in outpatient settings in Turkey are amoxicillin/clavulanate, an oral third-generation cephalosporin 'cefixime.' The most common agents used for parenteral treatment are aminoglycosides and parenteral cephalosporins (ceftriaxone or cefotaxime) in the case of patients under three months of age, toxic, or could not have oral intake. For secondary prophylaxis cefixime, co-trimoxazole and nitrofurantoin are commonly prescribed. Our study showed a significant increase in antimicrobial resistance to the most common antibiotics prescribed for UTI in childhood with the first UTI attack even in an outpatient setting. The resistance rates for amoxicillin-clavulanate, ampicillin-sulbactam, cefuroxime, ceftriaxone were almost $20 \%$ or above in our study. This result is striking because the frequency of cephalosporin resistance was nearly half in the previous study conducted at our center between $2004-2008$ years ${ }^{19}$, which included all positive UCs by not taking into consideration the comorbid factors, including urinary tract anomalies, recurrent UTI which assumed to increase the frequency of antimicrobial resistance. A comparison of antimicrobial resistance against uropathogens in consecutive (2004-2008, 2010-2016) periods in our center was shown in Fig. 1. These results indicate that UTI treatment will be troublesome in the future, even in an outpatient setting. These results are important because of heralding the risk of UTI complication burden. The significant increase in resistance to third-generation cephalosporins also harbors significant risks not only in UTI but also in other childhood disease treatments. 
Ghadageet al. ${ }^{21}$ reported increased resistance to commonly used empirical therapy -ampicillin and cotrimoxazole- for UTI in India. Kothari and Sagar ${ }^{22}$ also reported low susceptibility to amoxicillin, amoxicillin/clavulanate, ciprofloxacin, co-trimoxazole in uropathogens. Prais et al. ${ }^{23}$ reported that empirical treatment with co-trimoxazole or cephalexin as the initial drug is inadequate in approximately one-third of UTI cases, but that nitrofurantoin and nalidixic acid maintained their very high efficacy against urinary pathogens in Israel. The European Centre for Disease Prevention and Control reported the increasing resistance to antibiotic treatments, including carbapenems. ${ }^{24}$ Imipenem-resistant E. coli rates were reported at $1.4-3.5 \%$ in Turkey. ${ }^{8,25}$ In our study, while resistance to ampicillin, piperacillin, and TMPSMX was high among all isolates, imipenem, amikacin, and tobramycin had the lowest resistance. All Klebsiella isolates are sensitive to imipenem and amikacin in our study, as in a study by Abuhandan et al. ${ }^{26}$ However, Wang et al. reported resistance to imipenem and amikacin at a frequency of $21.12 \%$ and $6.83 \%$, respectively. ${ }^{6}$ These results may vary because of the different patient inclusion criteria in different studies. Proteus isolates also revealed no resistance to third-generation cephalosporins and imipenem in our study. The overall ESBL positivity has been reported to be $5 \%$ in Europe, $39 \%$ in Asia, and $30 \%-50 \%$ in Turkey. ${ }^{27,28}$. Kurt-Şükür et al. reported a prominently increase in overall ESBL positivity from $7.8-23.5 \%$ within ten years. ${ }^{8}$ ESBL positivity in our study was $5.6 \%$ in frequency, which is lower than the reports of other studies. This may because all of our patients had the first UTI episode without comorbid conditions and frequent antibiotic usage for UTI treatment. The increase of resistant strains can be attributed to either availability of the drugs for unnecessary and improper use of many antimicrobials, or by empirical treatment. ${ }^{29,30}$ Therefore, continuous surveillance, new strategies, and multidisciplinary actions should be developed against over consumption and unnecessary antibiotic treatments. Recently, in this context, the Turkish Ministry of Health restricted antibiotic intake without prescription and planned projects to improve rational antibiotic use, such as public education campaigns, to increase awareness about this topic. Studies in the future will show the results of these precautions. Our study has the following limitations. The major limitation was its retrospective nature. The history of previous UTI episodes was limited to the family expression and the investigations performed in our hospital. Another limitation relates to in vitro susceptibility testing, which may not be fully reflected in clinical outcomes, as in-vivo sensitivity may be different. Also, the results obtained from our study may not be valid for other patients in different regions.

\section{Conclusion}

The present study showed that initial empirical treatment with amoxicillin, trimethoprimsulfamethoxazole, and first-generation cephalosporins are no longer appropriate, but fluoroquinolones, cefepime, imipenem, amikacin and nitrofurantoin (for $E$. Coli) maintained their high efficacy against urinary pathogens in Turkey. Almost one in five children have antimicrobial resistance against antimicrobials which are the ones likely to be prescribed before culture results and antibiotic sensitivities are available to the clinician. This result reveals upcoming future challenges in the successful treatment of pediatric UTI, even in an outpatient setting. The present results may be of significant value to assist 
physicians in the appropriate choice of antibiotics, and to prevent the misuse or excessive use of antibiotics.

\section{Declarations}

Funding Source: No external funding for this manuscript

Financial Disclosure: Authors have indicated that they have no financial relationships relevant to this article to disclose

Conflict of interest: The authors declare no conflict of interest

\section{Contributors' Statement}

Dr Sari conceptualized and designed the study, drafted the initial manuscript, and reviewed, and revised the manuscript.

Drs Yazilitas, Oztek-Celebi, Akcaboy, and Akisoglu designed the data collection instruments, collected data, carried out the initial analyses, and reviewed and revised the manuscript. Prof. Senel conceptualized and designed the study, coordinated and supervised data collection, and critically reviewed the manuscript for important intellectual content.

All authors approved the final manuscript as submitted and agree to be accountable for all aspects of the work.

\section{References}

1. Korbel L, Howell M, Spencer JD. The clinical diagnosis and management of urinary tract infections in children and adolescents. Paediatr Int Child Health. 2017;37:273-9.

2. Konca C, Tekin M, Uckardes F, Akgun S, Almis H, Bucak IH, et al. Antibacterial resistance patterns of pediatric community-acquired urinary infection: Overview. Pediatr Int. 2017;59:309-15.

3. Tullus K. Outcome of post-infectious renal scarring. Pediatr Nephrol. 2015;30:1375-7.

4. Shaikh N, Mattoo TK, Keren R, Ivanova A, Cui G, Moxey-Mims M, et al. Early Antibiotic Treatment for Pediatric Febrile Urinary Tract Infection and Renal Scarring. JAMA Pediatr. 2016;170:848-54.

5. Karavanaki KA, Soldatou A, Koufadaki AM, Tsentidis C, Haliotis FA, Stefanidis CJ. Delayed treatment of the first febrile urinary tract infection in early childhood increased the risk of renal scarring. Acta Paediatr. 2017;106:149-54.

6. Wang J, He L, Sha J, Zhu H, Huang L, Zhu X, et al. Etiology and antimicrobial resistance patterns in pediatric urinary tract infection. Pediatr Int. 2018;60:418-22.

7. Erol B, Culpan M, Caskurlu H, Sari U, Cag Y, Vahaboglu H, et al. Changes in antimicrobial resistance and demographics of UTIs in pediatric patients in a single institution over a 6-year period. J Pediatr Urol. 2018;14:176.e1-176.e5. 
8. Kurt-Şükür ED, Özçakar ZB, Doğan Ö, Öztürk M, Karaman M, Çakar N, et al. The changing resistance patterns of bacterial uropathogens in children. Pediatr Int. 2020 Apr 29. doi: 10.1111/ped.14270. Online ahead of print.

9. Raupach T, Held J, Prokosch HU, Rascher W, Zierk J. Resistance to antibacterial therapy in pediatric febrile urinary tract infections-a single-center analysis. J Pediatr Urol. 2020;16:71-9.

10. Subcommittee on urinary tract infection. Reaffirmation of AAP Clinical Practice Guideline: The Diagnosis and Management of the Initial Urinary Tract Infection in Febrile Infants and Young Children 2-24 Months of Age. Pediatrics 2016;138 (6). pii: e20163026.

11. National Committee for Clinical Laboratory Standards. Performance Standards for Antimicrobial Susceptibility Testing. Twelfth Informational Supplement. NCCLS document M100-S12. Wayne, National Committee for Clinical Laboratory Standards, 2002.

12. Rasamiravaka T, Shaista Sheila HS, Rakotomavojaona T, Rokato-Alson AO. Rasamindrakotroka. Changing profile and increasing antimicrobial resistance of uropathogenic bacteria in Madagascar. Med Mal Infect. 2015;45:173-6.

13. Wu CT, Lee HY, Chen CL, Pao-Lan T, Cheng-Hsun C. High prevalence and antimicrobial resistance of urinary tract infection isolates in febrile young children without localizing signs in Taiwan. $J$ Microbiol Immunol Infect. 2016;49:243-8.

14. Robinson JL, Le Saux N. Management of urinary tract infections in children in an era of increasing antimicrobial resistance. Expert Rev Anti Infect Ther. 2016;14:809-16.

15. Rezaee MA, Abdinia B. Etiology and Antimicrobial Susceptibility Pattern of Pathogenic Bacteria in Children Subjected to UTI: A Referral Hospital-Based Study in Northwest of Iran. Med (Baltim). 2015;94:e1606.

16. Moore CE, Sona S, Poda S, Putchhat H, Kumar V, Sopheary S, et al. Antimicrobial susceptibility of uropathogens isolated from Cambodian children. Paediatr Int Child Health. 2016;36:113-7.

17. Sharef SW, El-Naggari M, Al-Nabhani D, Al Sawai A, Al Muharrmi Z, Elnour I, et al. Incidence of antibiotics resistance among uropathogens in Omani children. presenting with a single episode of urinary tract infection. J Infect Public Health. 2015;8:458-65.

18. Akhtar MS, Mohsin N, Zahak A, Ain MR, Pillai PK, Kapur P, et al. Antimicrobial sensitivity pattern of bacterial pathogens in urinary tract infections in South Delhi, India. Rev Recent Clin Trials. 2014;9:271-5.

19. Senel S, Karacan C, Erkek N, Gol N. A single-center experience of antimicrobial resistance patterns in pediatric urinary tract infection. Medical Principles Practice. 2010;19:359-63.

20. Koçak M, Büyükkaragöz B, Çelebi-Tayfur A, Çaltik A, Köksoy AY, Çizmeci Z, et al. Causative pathogens and antibiotic resistance in children hospitalized for urinary tract infection. Pediatr Int. 2016;58:46771.

21. Ghadage DP, Nale SS, Kamble DS, Muley VA, Wankhade AB, Mali RJ, Bhore AV. Study of Aetiology and Anti-biogram of Uropathogens in Children-A Retrospective Analysis. J Clin Diagn Res. 2014;8:20-2. 
22. Kothari A, Sagar V. Antibiotic resistance in pathogens causing community-acquired urinary tract infections in India: A multicenter study. J Infect Dev Ctries. 2008;2:354-8.

23. Prais D, Straussberg R, Avitzur Y, Nussinovitch M, Harel L, Amir J. Bacterial susceptibility to oral antibiotics in community-acquired urinary tract infection. Arch Dis Child. 2003;88:215-8.

24. European Centre for Disease Prevention and Control. Antimicrobial resistance surveillance in Europe in 2015. Annual Report of the European Antimicrobial Resistance Surveillance Network (EARS-Net). 2017, http://ecdc.europa.eu/en/publications/Publications/antimicrobial-resistance-europe-2015.pdf (accessed May 2019).

25. Demir M, Kazanasmaz H. Uropathogens and antibiotic resistance in the community and hospitalinduced urinary tract infected children. J Glob Antimicrob Resist. 2020;20:68-73.

26. Abuhandan M, Güzel B, Oymak Y, Çiftçi H. Antibiotic sensitivity and resistance in children with urinary tract infection in Sanliurfa. Turk J Urol. 2013;39:106-10.

27. Tseng MH, Lo WT, Lin WJ, Teng CS, Chu ML, Wang CC. Changing trend in antimicrobial resistance of pediatric uropathogens in Taiwan. Pediatr Int. 2008;50:797-800.

28. Flammang A, Morello R, Vergnaud M, Brouard J, Eckart P. Profile of bacterial resistance in pediatric urinary tract infections in 2014. Arch Pediatr. 2017;24:215-24.

29. Mueller $\mathrm{T}$, Östergren $\mathrm{PO}$. The correlation between regulatory conditions and antibiotic consumption within the WHO European Region. Health Policy. 2016;120:882-9.

30. Bryce A, Hay AD, Lane IF, Thornton HV, Wootton M, Costelloe C. Global prevalence of antibiotic resistance in paediatric urinary tract infections caused by Escherichia coli and association with routine use of antibiotics in primary care: systematic review and meta-analysis. BMJ. 2016;352:i939.

\section{Figures}


80

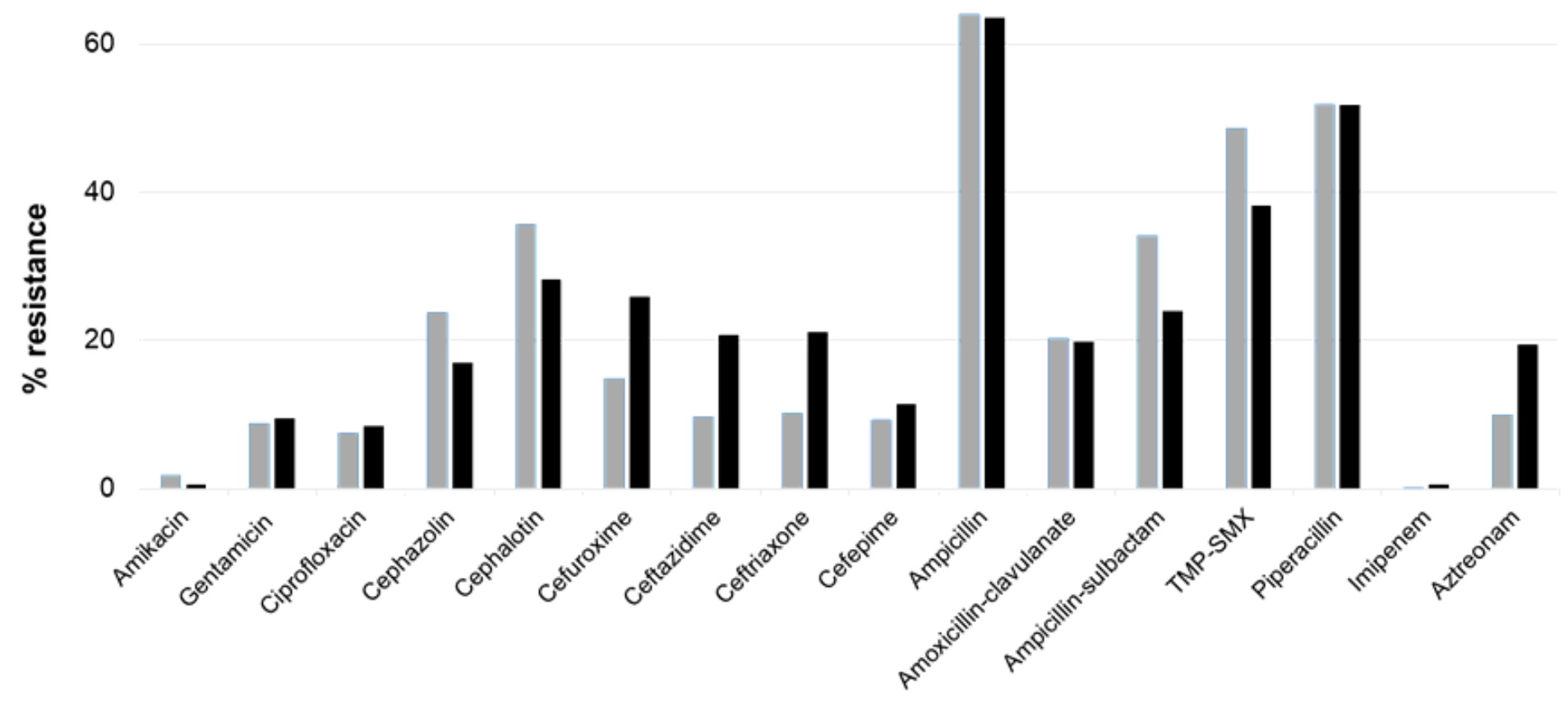

Figure 1

Comparison of antimicrobial resistance against uropathogens in two consecutive period in the same center 